Hence, clearly, the object indicated in the title is more perfectly attained, the thinner the plate and the smaller and more numerous the holes. Very fine wire cloth would answer the purpose better than any metal plate with holes drilled through it ; and very fine closely-woven cotton cloth, or cambric, answers better than the finest wire cloth. The impenetrability of wet cloth to air is well known to laundresses, and to every naturalist who has ever chanced to watch their operations. The quality of dry cloth to let air through with considerable freedom, and wet cloth to resist it, is well known to sailors, wet sails being sensibly more effective than dry sails (and particularly so in the case of old sails, and of sails of thin and light material).

An illustration was shown to the meeting by taking an Argand lamp-funnel, with a piece of very fine closely-woven cotton cloth tied over one end of it. When the cloth was dry, and the other end dipped under water, the water rose with perfect freedom inside, showing exceedingly little resistance to the passage of air through the dry cloth. When it was inverted, and the end guarded by the cloth was held under water, the water rose with very great freedom, showing exceedingly little resistance to the permeation of water through the cloth. The cloth being now wet, and the glass once more held with its other end under water, the cloth now seemed perfectly air-tight, even when pressed with air-pressure corresponding to nine inches of water, by forcing down the funnel, which was about nine inches long, till the upper end was nearly submerged. When it was wholly sub-

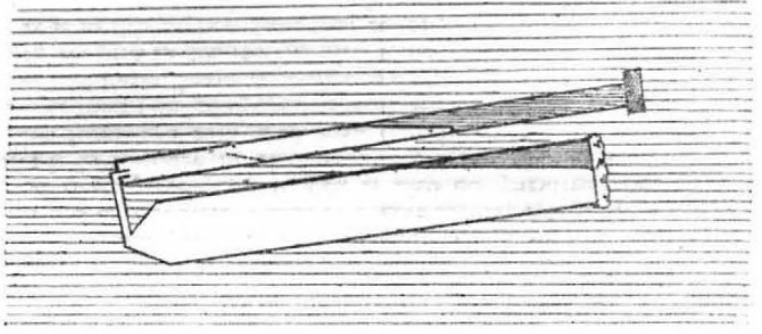

Water indicated by horizontal shading; Air by white paper.

merged, so that there was air on one side and water on the other, the resistance to permeation of air was as decided as it was when the cloth, very perfectly wet, had air on each side of it.

Once more, putting the cloth end under water; holding the tube nearly horizontal, and blowing by the mouth applied to the other end:-the water which had risen into the funnel before the mouth was applied, was expelled. After that no air escaped until the air-pressure within exceeded the water pressure on the outside of the cloth by the equivalent of a little more than nine inches of water; and when blown with a pressure just a very little more than that which sufficed to produce a bubble from any part of the cloth, bubbles escaped in a copious torrent from the whole area of the cloth.

The accompanying sketch represents the application to the Navigational Depth Gauge. The wider of the two communicating tubes, shown uppermost in the sketch, has its open mouth guarded by very fine cotton cloth tied across it. The tube shown lower in the diagram is closed for the time of use by a stopper at its lower end. A certain quantity of water (which had been forced into it during the descent of the gauge to the bottom of the sea) is retained in it while the gauge is being towed np to the surface in some such oblique position as that shown in the sketch. While this is being done the water in the wide tube is expelled by the expanding air. The object of the cloth guard is to secure that this water is expelled to the last drop before any air escapes; and that afterwards, while the gange is being towed wildly along the surface from wave to wave by a steamer running at fourteen or sixteen knots, not a drop of water shall re-enter the instrument.

\section{ON THE CLASSIFICATION OF BIRDS ${ }^{1}$}

$A$ BOUT twelve years ago Prof. Huxley had taken up the A subject of the classification of birds in his usual zealous and original way, and from quite a new point of view. Prof. Huxley, treating birds mainly from their bones and as if they were extinct

${ }^{x}$ Abstract of a paper read at the British Association by P. L. Sclater, M.A., Ph.D., F.R.S. animals of which these parts of their structure only were known, had proposed an entirely new plan of arrangement, based mainly upon the characteristic variations of the palatal bones, which had passed almost unnoticed by previous writers. The author, who had long been dissatisfied with the Cuvierian system, which with certain modifications he had employed up to 1872 , had in that year been constrained to consider the whole subject in order to decide what arrangements should be adopted in the "Nomenclator Avium Americanarum " (a joint work by Mr. O. Salon and himself), then ready for publication. Prof. Huxley had commenced his system with the lowest and most reptilian birds, and had ended it with the highest and most specialised. But it seemed to the author that by exactly reversing this arrangement he would obtain a scheme which would not very far deviate from that which he had previously employed for the first three orders, and would offer many improvements on the Cuvierian system in the remaining ones. Such a scheme had accordingly been promulgated in the Introduction to the "Nomenclator" and followed in that work. In the various subsequently issued editions of the "List of Vertebrated Animals in the Zoological Society's Gardens" a nearly similar arrangement had been followed. A certain amount of adbesion having been secured to this system, the author had been recently induced to devote some labour to its improvement and development. As now elaborated it did not profess to be in any respects original, except as regarded certain small details on points to which he had devoted special attention. The arrangement was in fact simply that of Huxley reversed, with slight modifications consequent upon the recent researches of Parker and Garrod on the anatomy and osteology of little known forms.

The author then proceeded to explain further the "Systema Avium " thus advocated, as shown in the subjoined table, in which the approximate number of known species was added after each Order.

\section{ORDERS OF EXISTING BIRDS \\ SubClass Carinate (I0,12I SPECIES)}

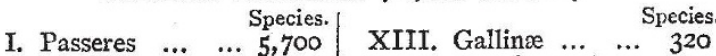

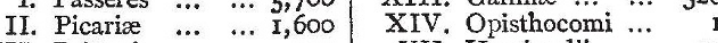

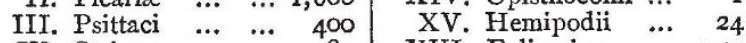

IV. Striges $\quad \cdots \quad$...

V. Accipitres... $\quad \ldots \quad 330$ XVII. Alectorides $\ldots . .60$

VI. Steganopodes ... 60 XVIII. Limicolæ $\quad \ldots \quad 250$

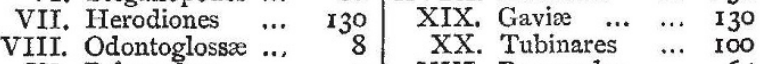

IX. Palamedeæ $\quad \ldots \quad 3$ XXI. Pygopodes $\quad \ldots \quad 65$

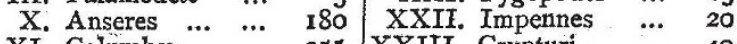

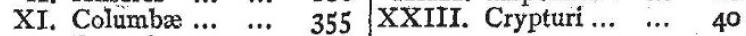
XII. Pterocletes $\ldots . \quad 15$

SUBClasS RATtTE (18 SPECIES)

\begin{tabular}{llll|lll} 
XXIV. Apteryges ... & $\ldots$ & 4 & XXVI. Struthiones & $\ldots$ & 4
\end{tabular}

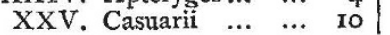

In submitting this arrangement, as one which on the whole he was disposed to regard as the best to be adopted after many years' study of the Class of Birds, the author observed that it should be recollected that, although a linear system is an absolute necessity for practical use, it could never be a perfectly natural one. It would always be found that certain groups were nearly equally related to others in different places in the linear series, and that it was a matter of difficulty to decide with which of the allied forms they were best located. But, a linear arrangement being an absolute necessity, it became our duty to make it as natural as possible.

\section{THE GREEN COLOUR OF OYSTERS}

IN NATURE, vol, xvi. p. 397 , mention was made of the fact 1 that the green colour observed in oysters in certain localities is caused by a variety of navicula, to which the name Navicula ostrearia has been given. Further particulars of experiments made by M. Puységur, at Sissable, are not without interest. ${ }^{2}$

"The green slime was collected by lightly scraping the margin of one of the 'clears' with a spoon, and was put in flasks, shaken for a moment and then allowed to settle, so as to get rid of the mud, some admixture of which is inevitable. The coloured fluid, containing little or nothing besides diatoms, was then poured off into other flasks. Care and some little dexterity are requisite, as if there is too much silt or too large a quantity

$$
\text { I Revue maritime et coloniale, February, } \mathbf{1 8 8 0} \text {. }
$$

